\title{
CORRESPONDENCE
}

\section{Comment on Oral White Lesions Associated with Chewing Khat}

\author{
Dr. Ali Aiman \\ P O Box 60710 Dammam 31555 Saudi Arabia. \\ Telephone: +966504742633 Fax: +96638251750. \\ E-mail:aiman-a-li@maktoob.com
}

\section{Dear Editor,}

I have read the nice paper published in your estimable journal of Tobacco Induced Diseases Vol. 2, No. 3: 145-150 (2004) about "Oral White Lesions Associated with Chewing Khat". This was a clinical descriptive study done by Gorsky et al. on 47 Yemeni Israeli who had chewed khat more than 3 years and 55 Yemeni nonchewers as group control.

I kindly wanted to express my thoughts about some points mentioned in the paper including:

1. The phrase [chewing khat] mentioned in the paper is a misnomer and should be replaced by "takhzeen al-qat" as chewing does not infer the exact meaning of what Yemeni people used to do. They used to do "takhzeen" which means in Arabic chewing and storing of qat for several hours. Therefore, the Arabic word takhzeen is used to properly describe this habit1. And the word qat with letter "q" is more commonly used than khat, particularly in the recent studies 1-3.

2. The authors addressed people who chewed qat for more than 3 years (neglecting the frequency) as chronic chewers, in fact chronocity is dependent on two main factors; the duration (time in years), and frequency of chewing per week. For instance, many persons may use qat for more than 10 years in low frequency (once per month), yet, not considered as chronic users. On the other hand, others may practise it daily for only 2 years and considered as chronic. A recent study strongly correlated the effect of this habit with the frequency

3. The authors mentioned in their study a very exaggerated percentages of white lesions in both control $(16 \%)$ and chewer $(83 \%)$ groups. Whereas the highest international reported incidence 4 of oral white lesions among the normal population is not more than $11.6 \%$ and among qat chewers $1(n=1528)$ is $22.3 \%$. Furthermore, the authors did not mention any description for the white lesions they found in the control group. What types of white lesions were found?

4. The authors addressed $14.6 \%$ of the diagnosed white lesions as nonhomogenous, at the same time they said "No white lesion was felt to be clinically suspicious for malignant or premalignant changes", on the other hand, non-

homogenous white lesions are considered in the international reports as aggressive lesions5-7. Moreover, the occurrence of such lesions is in contrary with most of other studies which reported that takhzeen al-qat may only cause homogenous or benign changes in the oral and esophagus mucosa 1,8-10.

5. Finally, all recent references cited in this paper are not related to qat habit but to 
other habits in other regions of the world. While authors did not quote several studies done in the last 10 years on this habit in the Middle East, which are available through the Medline1-3,11,12.

Looking forward to hearing from you

Yours sincerely

Ali A. A.

\section{REFERENCES:}

1. AIMAN A. ALI, AL-SHARABI AK, AGUIRRE JM, NAHAS R. A study of 342 oral keratotic white lesions induced by takhzeen al-qat among 2500 Yemeni. J Oral Pathol Med 2004; 33: 368-72.

2. HASSAN NM, GUNAID AA, ABDULLA AA, ABDULKADER ZY, ALMANSOOB MK, AWAD AY. The effect of qat chewing on blood pressure and heart rate in healthy volunteers. J Trop Doc 2000; 30: 107-108.

3. AL-HADRANI A and THABET AAM. Acute adverse health effects of pesticides sprayed on qat trees. J Pest. Control and Enveron. Science 2000; 8(1): 97-106.

4. AIMAN A. Evaluaci\&oacute;n de par\&aacute; metros clinicopatol\&oacute;gicos de importancia pron\&oacute;stica en la leucoplasia oral. Tesis Doctoral. Leioa (Spain): Universidad del Pa\&iacute;s Vasco/EHU, 1997. P: 1112.

5. VAN DER WAAL I and SCHEPMAN KP. A modified classification and staging systems for oral leukoplakia. Oral Oncol 2000; 36: 264-266.

6. AXELL T, PINDBORG JJ, SMITH CJ, VAN DER WALL I. International collaborative group on oral white lesions with special reference to precancerous and tobacco related lesions: Conclusion of an international symposium held in Uppsala, Sweden. J O Pathol Med 1996; 25: 49-54.

7. AXELL T, HOLMSTRUP P, KRAMER IR, Pindborg JJ, Shear M. International seminar on oral leukoplakia and associated lesions to tobacco habits. 1983; Malmo. Comm Dent Oral Epidemiol 1984; 12: 145-154.

8. EL-GUNAID A, EL-SHERIF AN, MURRAY-LYON IM, ZUREIKAT N and SHUSHA S. Effect of chewing qat on the mucosal histology and prevalence of helicobacter pylori in the esophagus, stomach and duodenum of Yemeni patients. Histology 1991; 19: 437-443.

9. Aiman A. Ali. Common oral diseases related to qat chewing in Yemen. Journal of Damascus University (Arabic) 2003; 19 (1): 143-159.

10. Aiman A. Ali, Ali A. AL-SHARABI. A pilot study on the histopathological changes in oral mucosa induced by takhzeen al-qat. Journal of Damascus University (Arabic) 2004; 20(1): 217-229.

11. ATTEF OA, ALI AA and ALI HM. Effect of khat chewing on bioavailability of ampicillin and amoxicillin. J Antimicro Chemoth 1997; 39: 523-525.

12. NASHER AA, QIRBI AA, and GHAFOOR MA. Khat chewing and neck bladder dysfunction. A randamised controlled trial of -adrenergic blockade. $\mathrm{Br}$ J Urology 1995; 75: 597-598. 